\title{
Radiation therapy for oligometastatic bone disease in breast cancer
}

\author{
Norihisa Katayama, Kuniaki Katsui, Kenta Watanabe, Ryota Nagao, Kaho Otsuki, Takao Hiraki, \\ Susumu Kanazawa
}

Department of Radiology, Okayama University Medical School, Okayama, Japan

Contributions: (I) Conception and design: N Katayama, K Katsui, K Watanabe, T Hiraki, S Kanazawa; (II) Administrative support: T Hiraki, S Kanazawa; (III) Provision of study materials or patients: N Katayama, K Watanabe, R Nagao, K Otsuki; (IV) Collection and assembly of data: N Katayama, K Watanabe, R Nagao, K Otsuki; (V) Data analysis and interpretation: N Katayama, K Watanabe, R Nagao, K Otsuki ; (VI) Manuscript writing: All authors; (VII) Final approval of manuscript: All authors.

Correspondence to: Norihisa Katayama, MD, PhD. Department of Radiology, Okayama University Medical School, 2-5-1 Shikata-cho, Okayama 7008558, Japan. Email: n-katayama@bea.hi-ho.ne.jp.

\begin{abstract}
Breast cancer (BCa) frequently metastasizes to the bone. $\mathrm{BCa}$ patients with oligometastatic bone diseases have much more favorable outcomes than those with metastatic bone disease. Radiation therapy (RT), especially stereotactic body radiation therapy (SBRT), is advised for the treatment of patients with oligometastatic bone disease in other primary sites. This line of treatment provided favorable outcomes in patients and resulted in only mild toxicities. A similar strategy has been suggested for treatment of BCa patients with oligometastatic bone disease. $\mathrm{BCa}$, bone-only, or high radiation dose are reported to have been associated with good outcomes in RT for metastatic disease. Furthermore, based on the guidelines provided by the BCa expert panel of the German Society for Radiation Oncology and members of the Working Party of Gynecologic Oncology Breast Committee and in line of the results obtained in other primary sites, our group supports the use of high-dose RT or SBRT for the treatment of BCa patients with oligometastatic bone disease. Additionally, the use of magnetic resonance imaging (MRI) for proper target volume definition and three-dimensional (3D) treatment planning especially for lesions of the trunk are essential for the treatment planning of RT. Of note, several clinical trials have combined RT with immune checkpoint inhibitors for the treatment of BCa patients with metastatic disease. Based on this, we anticipate that combined RT and ICI may serve as a better treatment modality for BCa patients with oligometastatic bone disease.
\end{abstract}

Keywords: Bone metastasis; breast cancer (BCa); oligometastatic; radiation therapy (RT); stereotactic body radiation therapy (SBRT)

Submitted Dec 13, 2019. Accepted for publication Jan 06, 2020.

doi: $10.21037 /$ tcr.2020.01.35

View this article at: http://dx.doi.org/10.21037/tcr.2020.01.35

\section{Introduction}

Bone is the most common site for metastasis in breast cancer (BCa) (1). In about $20 \%$ of the patients, tumors of the breast metastasize to the bone. Moreover, bone metastasis (BM) occurs in more than half of the cases showing distant metastases (2). Additionally, up to $70 \%$ of the patients who succumb to BCa show evidence of metastatic bone disease, post-mortem (3). BCa patients with first $\mathrm{BM}$ have a median survival time of about 20 months, and a 10\% 5-year survival rate (4). Whereas, the 5-year survival rate for BCa patients with singular or oligometastatic bone disease is in the favorable range of $58.4-83 \%(5-7)$.

The treatment of patients with BM includes the systemic administration of antitumor and antiresorptive agents, and/ or localized radiation therapy (RT), radiofrequency ablation, 
Table 1 RT for oligometastatic bone disease in other primary sites

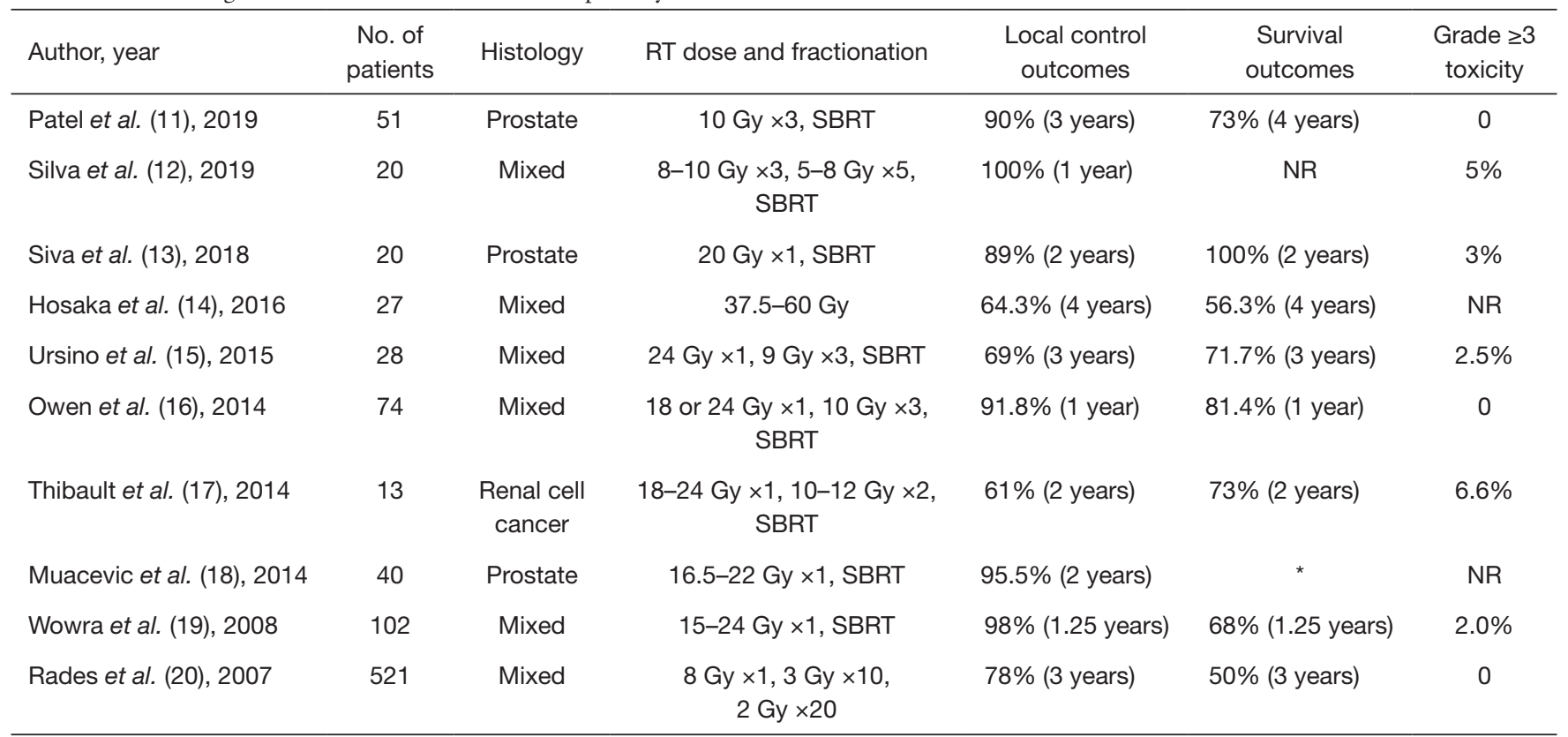

*, the $75 \%$ survival proportion was achieved at 17.5 months. RT, radiation therapy; SBRT, stereotactic body radiotherapy; NR, not reported.

and surgery. RT especially plays an important role due to the radiosensitivity of BCa cells (8). Pain, limited movements, risk of fracture, after surgical intervention, and spinal cord compression are the indications for palliative RT (9). While pain relief is generally observed within a few days after the start of RT, radiologically detectable recalcification and stabilization commence at the earliest within 6-12 weeks after termination of RT. Moreover, asymptomatic patients with favorable prognostic factors can be treated using RT (10). Furthermore, high-dose RT may provide long-term localized control from skeletal manifestations and improve the overall survival (OS) of patients with oligometastases.

Here, we have described RT for the treatment of patients with oligometastatic bone disease in other primary sites and in $\mathrm{BCa}$, and the future perspectives.

\section{RT for oligometastatic bone disease in other primary sites}

Some studies have opted RT for oligometastatic bone disease in other primary sites (Table 1) (11-20), and 8 of these 10 studies have used stereotactic body radiation therapy (SBRT). Sixty-seven percent of Grade $\geq 3$ toxicities were fractures requiring a surgery. Overall, they resulted in excellent outcomes with mild toxicities.
A recent SABR-COMET randomized phase II study (21) has compared the responses to SBRT (30-60 Gy in 3-4 fractions or 16-24 Gy in single fraction) and conventional RT (8 Gy in single fraction to 30 Gy in 10 fractions) in 99 patients who had a controlled primary malignancy with 1-5 metastatic lesions in mixed primary sites. Amongst these, about $33.5 \%$ account for metastases to the bone. The median OS in the conventional RT group was 28 months as compared to 41 months in the SBRT group $(\mathrm{P}=0.090$; where $\mathrm{P}<0.20$ designates a positive trial). Adverse events of grade 2 or worse occurred in $9 \%$ of conventional RT group compared to $29 \%$ in the SBRT group $(\mathrm{P}=0.026)$. Additionally, treatment-related deaths occurred in $4.5 \%$ cases in the SBRT group, while no deaths occurred in the conventional RT group.

Several studies recommend SBRT for treatment of oligometastatic bone disease (22-31). The American College of Radiology Appropriateness Criteria suggests that aggressive local therapy of oligometastatic spine disease may provide survival benefit to the patients, although additional data would be required to understand the role of highly conformal RT techniques that allow for radiation dose escalation (32). The evidence-based guidelines of The American Society for Radiation Oncology (ASTRO) do not describe the use of curative intent SBRT for treatment of 
Table 2 RT for oligometastatic bone disease in $\mathrm{BCa}$

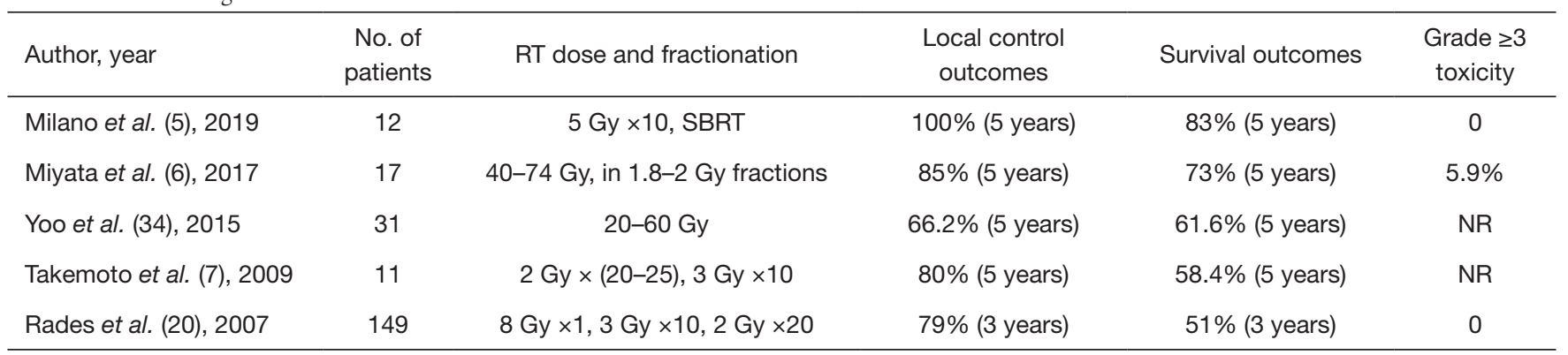

$\mathrm{RT}$, radiation therapy; $\mathrm{BCa}$, breast cancer; SBRT, stereotactic body radiotherapy; NR, not reported.

oligometastatic bone disease (33). Instead, the guidelines suggest that eligible patients with metastases to the spine be considered for available SBRT trials to clarify the role of optimal treatment approach.

\section{RT for oligometastatic bone disease in BCa}

Few studies suggest RT for treatment of patients with oligometastatic bone disease in BCa (Table 2) (5-7,19,34). In these studies, only a single patient presented grade 3 acute dermatitis with grade $\geq 3$ toxicity. Overall, patients received a high radiation dose that resulted in favorable outcomes, and mild toxicities. Here, Milano et al. (5) reported that the 5- and 10-year OS rates after SBRT were $83 \%$ and $75 \%$, respectively, for bone-only patients vs. $31 \%$ and $17 \%$, respectively, for other patients $(\mathrm{P}=0.002)$. Next, Rades et al. (20) suggest that the outcomes were most favorable in patients with myeloma/lymphoma followed by those with $\mathrm{BCa}$, and that none of the $\mathrm{BCa}$ patients showed progression of motor deficits. Additionally, Yoo et al. (34) reported that high-dose RT ( $\left.\geq 50 \mathrm{~Gy}_{10}\right)$ and HER2-negative status were significantly associated with improved local control, and Takemoto et al. (7) reported that local recurrence was observed in a patient treated with $3 \mathrm{~Gy} \times 10$ irradiation, the lowest dose among the eleven patients.

In a prospective study by Owen et al. (16), 74 patients with non-spine bone oligometastases (inclusive of $8 \% \mathrm{BCa}$ ) treated with SBRT were administered 18 Gy or 24 Gy in a single fraction, or $30 \mathrm{~Gy}$ in 3 fractions. Of these, six patients with $\mathrm{BCa}$ did not present with local recurrence, although seven of 68 patients with other primary sites did. Also, the number of metastases at simulation ( $<5 v s .>5$ metastases) was associated with reduced median OS post SBRT $(10.8$ vs. 6.4 months; $\mathrm{P}<0.0001)$. Next, in a retrospective study by Kobayashi et al. (35), 35 of 75 patients with oligometastatic
BCa (39\% bone) were treated with systemic chemotherapy plus metastasis-directed surgery or RT, and 40 patients were treated with systemic chemotherapy only. The 10and 20 -year OS rates were $82 \%$ and $53 \%$, respectively in patients with multidisciplinary treatments vs. $42 \%$ and $23 \%$, respectively in patients treated with systemic therapy alone $(\mathrm{P}=0.0063)$. Jacobson et al. (36) analyzed the number of sites of initial involvement identified in radionuclide bone scans in relation to long-term outcome in $113 \mathrm{BCa}$ patients with bone as the sole initial site of metastatic disease. Median survival from time of recurrence and time of original diagnosis for the three bone scan categories was one lesion $(\mathrm{n}=47), 53$ and 86 months; two lesions $(\mathrm{n}=22), 38$ and 68 months; and $\geq 3$ lesions ( $\mathrm{n}=44), 22$ and 58 months $(\mathrm{P}<0.0001$ and $\mathrm{P}<0.005$ for 1 and 2 lesions vs. $\geq 3)$.

Of note, none of the randomized clinical trials compares the effect of systemic chemotherapy plus RT with systemic chemotherapy alone for $\mathrm{BCa}$ patients with oligometastatic bone disease. However, the increased use of high-dose RT for treating oligometastatic bone disease, particularly in patients with $\mathrm{BCa}$, as a "routine" option in many hospitals has made it difficult to conduct prospective randomized trials (37). The BCa expert panel of the German Society for Radiation Oncology and members of the Working Party of Gynecologic Oncology Breast Committee recommends a full dose-fractionated regimen, e.g., 2 Gy $\times 20-25$ cycles, for RT of BCa patients with oligometastatic bone disease (8). Accordingly, by combining the results of RT for oligometastatic bone disease in other primary sites, we recommend high-dose RT or SBRT for BCa patients with oligometastatic bone disease.

Technically, the gross tumor volume (GTV) is the tumor visible in the magnetic resonance imaging (MRI) scans. In clinically suspected intradural extension, contrastenhanced MRI is recommended to delineate the meningeal 
enhancement and is included in the GTV. The clinical target volume (CTV) includes the GTV with an adequate (e.g., 1-2 cm) margin. Of note, the CTV should always include the complete vertebral body in case of vertebral body involvement. In the case of unaffected compacta, extension of the CTV beyond the compacta is discouraged (8). The planning target volume (PTV) margin differs based on factors such as the use of image-guided radiotherapy (IGRT) or not, the method of IGRT, reproducibility, and respiratory motion. Furthermore, the three-dimensional (3D) treatment planning is essential, especially for lesions of the trunk, because the treatment of oligometastatic bone disease requires high-dose RT and checking the irradiated dose and volume of adjacent normal tissue.

\section{Future perspectives}

Based on the current scenario, combined use of RT and immune checkpoint inhibitors (ICI) may enhance the antitumor immune response and produce a synergistic effect (38). The randomized double-blind international phase III PACIFIC trial (39) compared the effect of durvalumab as consolidation therapy with placebo in 713 patients with stage III locally advanced unresectable non-small cell lung cancer after treatment with platinum-based definitive chemoradiotherapy. The 24 -month OS rate was $66.3 \%$ in the durvalumab group, as compared to $55.6 \%$ in the placebo group (two-sided $\mathrm{P}=0.005$ ). Durvalumab significantly prolonged OS, as compared with placebo (stratified hazard ratio for death, 0.68; $\mathrm{P}=0.0025)$. Chicas-Sett et al. in their systematic review discussed the effect of combined RT and ipilimumab in patients with metastatic melanoma (40), where a survival benefit of eight months in favor of the RT plus ipilimumab combination was observed in comparison with the median OS of 11.4 months in the pooled analysis of phase II and III trials of ipilimumab without RT.

Furthermore, there are several ongoing and completed clinical trials combining RT and ICI in metastatic BCa patients (41). In future, the combined use of RT and ICI may serve as a promising therapeutic option against oligometastatic bone disease in $\mathrm{BCa}$.

\section{Conclusions}

Based on results from several studies, the overall survival of $\mathrm{BCa}$ patients with oligometastatic bone disease is favorable compared to those with metastatic bone disease. Furthermore, we recommend high-dose RT or SBRT for patients with oligometastatic bone disease. The use of MRI for proper target volume definition and 3D treatment planning especially for lesions of the trunk are essential for the treatment planning of RT. Finally, we anticipate that combinatorial treatment using RT and ICI may benefit BCa patients with oligometastatic bone disease.

\section{Acknowledgments}

Funding: None.

\section{Footnote}

Provenance and Peer Review: This article was commissioned by the Guest Editors (Tadahiko Shien and Kaori Terata) for the series "Loco regional therapy for metastatic breast cancer" published in Translational Cancer Research. The article was sent for external peer review organized by the Guest Editors and the editorial office.

Conflicts of Interest: All authors have completed the ICMJE uniform disclosure form (available at http://dx.doi. org/10.21037/tcr.2020.01.35). The series "Loco-regional therapy for metastatic breast cancer" was commissioned by the editorial office without any funding or sponsorship. The authors have no other conflicts of interest to declare.

Ethical Statement: The authors are accountable for all aspects of the work in ensuring that questions related to the accuracy or integrity of any part of the work are appropriately investigated and resolved.

Open Access Statement: This is an Open Access article distributed in accordance with the Creative Commons Attribution-NonCommercial-NoDerivs 4.0 International License (CC BY-NC-ND 4.0), which permits the noncommercial replication and distribution of the article with the strict proviso that no changes or edits are made and the original work is properly cited (including links to both the formal publication through the relevant DOI and the license). See: https://creativecommons.org/licenses/by-nc-nd/4.0/.

\section{References}

1. Fujino M, Suzuki K, Nishio M, et al. Strategy of radiation therapy for bone metastases and MSCC in breast cancer patients. Breast Cancer 2011;18:238-43.

2. Coleman RE. Clinical features of metastatic bone 
disease and risk of skeletal morbidity. Clin Cancer Res 2006; 12:6243s-9s.

3. Galasko C. The anatomy and pathways of skeletal metastases. In: Weiss L, Gilbert A (eds). Bone metastases. Boston: GK Hall, 1981:49-63.

4. Leto G. Current status and future directions in the treatment of bone metastases from breast cancer. Clin Exp Pharmacol Physiol 2019;46:968-71.

5. Milano MT, Katz AW, Zhang H, et al. Oligometastatic breast cancer treated with hypofractionated stereotactic radiotherapy: Some patients survive longer than a decade. Radiother Oncol 2019;131:45-51.

6. Miyata M, Ohguri T, Yahara K, et al. Salvage radiotherapy for solitary metachronous bone metastasis in patients with breast cancer. Anticancer Res 2017;37:2575-9.

7. Takemoto M, Niibe Y, Kaneyasu Y, et al. Radiation therapy for isolated osseous metastasis of breast cancer in perspective of oligo-recurrence. Jpn J Clin Radiol 2009;54:516-9.

8. Souchon R, Feyer P, Thomssen C, et al. Clinical recommendations of DEGRO and AGO on preferred standard palliative radiotherapy of bone and cerebral metastases, metastatic spinal cord compression, and leptomeningeal carcinomatosis in breast cancer. Breast Care 2010;5:401-7.

9. Souchon R, Wenz F, Sedlmayer F, et al. DEGRO practice guidelines for palliative radiotherapy of metastatic breast cancer: bone metastases and metastatic spinal cord compression (MSCC). Strahlenther Onkol 2009;185:417-24.

10. Feyer PC, Steingraeber M. Radiotherapy of bone metastasis in breast cancer patients - Current approaches. Breast Care 2012;7:108-12.

11. Patel PH, Chaw CL, Tree AC, et al. Stereotactic body radiotherapy for bone oligometastatic disease in prostate cancer. World J Urol 2019;37:2615-21.

12. Silva SR, Gliniewicz A, Martin B, et al. Oligometastatic Disease State Is Associated with Improved Local Control in Patients Undergoing Three or Five Fraction Spine Stereotactic Body Radiotherapy. World Neurosurg 2019;122:e342-8.

13. Siva S, Bressel M, Murphy DG, et al. Stereotactic Abative Body Radiotherapy (SABR) for Oligometastatic Prostate Cancer: A Prospective Clinical Trial. Eur Urol 2018;74:455-62.

14. Hosaka S, Katagiri H, Honda Y, et al. Clinical outcome for patients of solitary bone only metastasis. J Orthop Sci 2016;21:226-9.

15. Ursino S, Montrone S, Cantarella M, et al. Stereotactic body radiotherapy of bone metastases in oligometastatic disease: Prognostic factors of oncologic outcomes. Tumori 2016;102:59-64.

16. Owen D, Laack NN, Mayo CS, et al. Outcomes and toxicities of stereotactic body radiation therapy for non-spine bone oligometastases. Pract Radiat Oncol 2014;4:e143-9.

17. Thibault I, Al-Omair A, Masucci GL, et al. Spine stereotactic body radiotherapy for renal cell cancer spinal metastases: Analysis of outcomes and risk of vertebral compression fracture. J Neurosurg Spine 2014;21:711-8.

18. Muacevic A, Kufeld M, Rist C, et al. Safety and feasibility of image-guided robotic radiosurgery for patients with limited bone metastases of prostate cancer. Urol Oncol 2013;31:455-60.

19. Wowra B, Zausinger S, Drexler C, et al. CyberKnife radiosurgery for malignant spinal tumors: characterization of well-suited patients. Spine 2008;33:2929-34.

20. Rades D, Veninga T, Stalpers LJA, et al. Outcome after radiotherapy alone for metastatic spinal cord compression in patients with oligometastases. J Clin Oncol 2007;25:50-6.

21. Palma DA, Olson R, Harrow S, et al. Stereotactic ablative radiotherapy versus standard of care palliative treatment in patients with oligometastatic cancers (SABRCOMET): a randomised, phase 2, open-label trial. Lancet 2019;393:2051-8.

22. Shiloh R, Krishnan M. Radiation for Treatment of Painful Bone Metastases. Hematol Oncol Clin North Am 2018;32:459-68.

23. Dunne EM, Fraser IM, Liu M. Stereotactic body radiation therapy for lung, spine and oligometastatic disease: current evidence and future directions. Ann Transl Med 2018;6:283.

24. Kougioumtzopoulou A, Zygogianni A, Liakouli Z, et al. The role of radiotherapy in bone metastases: A critical review of current literature. Eur J Cancer Care (Engl) 2017. doi: 10.1111/ecc.12724.

25. De Bari B, Alongi F, Mortellaro G, et al. Spinal metastases: Is stereotactic body radiation therapy supported by evidences? Crit Rev Oncol Hematol 2016;98:147-58.

26. Ahmed KA, Torres-Roca JF. Stereotactic body radiotherapy in the management of oligometastatic disease. Cancer Control 2016;23:21-9.

27. Taunk NK, Spratt DE, Bilsky M, et al. Spine radiosurgery in the management of renal cell carcinoma metastases. J Natl Compr Canc Netw 2015;13:801-9.

28. Gerszten PC. Spine metastases: from radiotherapy, surgery, to radiosurgery. Neurosurgery 2014;61 Suppl 
1:16-25.

29. Chan NK, Abdullah KG, Lubelski D, et al. Stereotactic radiosurgery for metastatic spine tumors. J Neurosurg Sci 2014;58:37-44.

30. Gerszten PC, Mendel E, Yamada Y. Radiotherapy and radiosurgery for metastatic spine disease: what are the options, indications, and outcomes? Spine 2009;34:S78-92.

31. Sahgal A, Larson DA, Chang EL. Stereotactic Body Radiosurgery for Spinal Metastases: A Critical Review. Int J Radiat Oncol Biol Phys 2008;71:652-65.

32. Lo SSM, Lutz ST, Chang EL, et al. ACR appropriateness criteria ${ }^{\circledR}$ spinal bone metastases. J Palliat Med 2013;16:9-19.

33. Lutz S, Balboni T, Jones J, et al. Palliative radiation therapy for bone metastases: Update of an ASTRO Evidence-Based Guideline. Pract Radiat Oncol 2017;7:4-12.

34. Yoo GS, Yu J Il, Park W, et al. Prognostic factors in breast cancer with extracranial oligometastases and the appropriate role of radiation therapy. Radiat Oncol J 2015;33:301-9.

35. Kobayashi T, Ichiba T, Sakuyama T, et al. Possible clinical cure of metastatic breast cancer: Lessons from our 30-year experience with oligometastatic breast cancer patients and literature review. Breast Cancer 2012;19:218-37.

36. Jacobson AF, Shapiro CL, Van Den Abbeele AD, et

Cite this article as: Katayama N, Katsui K, Watanabe K, Nagao R, Otsuki K, Hiraki T, Kanazawa S. Radiation therapy for oligometastatic bone disease in breast cancer. Transl Cancer Res 2020;9(8):5096-5101. doi: 10.21037/tcr.2020.01.35 al. Prognostic significance of the number of bone scan abnormalities at the time of initial bone metastatic recurrrence in breast carcinoma. Cancer 2001;91:17-24.

37. Ricardi U, Badellino S, Filippi AR. Clinical applications of stereotactic radiation therapy for oligometastatic cancer patients: A disease-oriented approach. J Radiat Res 2016;57:i58-i68.

38. Iheagwara UK, Clump DA, Heron DE.

Immunoradiosurgery: The convergence of SBRT and the immune response. In: Heron DE, Huq MS, Herman JM (eds). Stereotactic Radiosurgery and Stereotactic Body Radiation Therapy (SBRT). New York: Demos Medical Publishing, 2018:321-9.

39. Antonia SJ, Villegas A, Daniel D, et al. Overall survival with durvalumab after chemoradiotherapy in stage III NSCLC. N Engl J Med 2018;379:2342-50.

40. Chicas-Sett R, Morales-Orue I, Rodriguez-Abreu D, et al. Combining radiotherapy and ipilimumab induces clinically relevant radiation-induced abscopal effects in metastatic melanoma patients: A systematic review. Clin Transl Radiat Oncol 2017;9:5-11.

41. Hu ZI, Ho AY, McArthur HL. Combined Radiation Therapy and Immune Checkpoint Blockade Therapy for Breast Cancer. Int J Radiat Oncol Biol Phys 2017;99:153-64. 